\title{
sciendo
}

LanCog Lectures in Metaphysics 2013

\section{Dispensing with Ontological Levels: an Illustration ${ }^{1}$}

\author{
Peter van Inwagen \\ The University of Notre Dame
}

DOI: $10.2478 /$ disp-2014-0002

BIBLID [0873-626X (2014) 38; pp. 25-43]

Does metaphysics, or does it not, need ontological levels? Should metaphysics endorse the thesis that things of some kinds are ontologically more fundamental than things of some other kinds? Must it be a datum of metaphysics that entities of certain kinds are ontologically grounded in entities of certain other kinds? Must it be a feature of any adequate metaphysical theory that it awards a special ontological status to entities of certain kinds and denies this special status to entities of other kinds?

There are two ways to approach these questions (or this question - for the four questions I have asked are essentially the same question). I'll call them, tendentiously perhaps, the Bad Way and the Good Way. This is the Bad Way:

Begin by giving examples of pairs of things that supposedly occupy different ontological levels (or one of which is ontologically more fundamental than the other or one of which is ontologically grounded in the other or one of which enjoys a special ontological status denied to the other). Proceed to use these examples as intuition pumps in the service of an affirmative answer to our question. Alternatively, play the other side of the game: insist that the default answer to our question is No, and dispute the examples that your opponents say support an affirmative answer - deny the existence of some of the entities that figure in the examples, or deny that there is any reason to suppose that the members of any of the pairs do occupy different ontological levels. (And similarly for the other formulations of the question.)

${ }^{1}$ This paper is the text of the second of two LanCog Lectures in Metaphysics, which were presented at the University of Lisbon on 12 and 14 June, 2013.

Disputatio, Vol. VI, No. 38, May 2014

Received: 15/10/2013 Accepted: 15/10/2013 
And this is the Good Way:

Let metaphysicians who accept the idea of ontological levels construct theories that incorporate that idea. Let metaphysicians who reject the idea of ontological levels construct theories that do not incorporate that idea. Once these things have been done - of course they will be done only if they are possible, only if it is possible to construct theories of both sorts - compare all the theories that our metaphysicians have constructed and determine which is the best. (I say 'is' for the sake of simplicity; in this paper, I'll use 'metaphysical theory' to mean something fairly comprehensive, something like a metaphysical system — something sufficiently comprehensive that any two "metaphysical theories" will be incompatible with each other. Thus, platonic realism and presentism are not metaphysical theories in the present comprehensive sense; but any metaphysical theory must in some way incorporate a theory of universals and a theory of time.) And again, for no better reason than my desire to keep the sentences I have to write as simple as possible - I'll ignore the possibility of two metaphysical theories tying for first place in the goodness sweepstakes.) And, finally, affirm the reality of ontological levels only if ontological levels figure in the best metaphysical theory. (And similarly for the other formulations of the question.)

Granted, to become a follower of the Good Way is to commit oneself to finding a way to decide which metaphysical theory is the best one. But that would seem to be a problem that we metaphysicians are going to have somehow to deal with simply in virtue of being metaphysicians. (At the very least, most metaphysicians will concede that there are in metaphysics positions worthy of being called theories, and most metaphysicians will regard some of these theories as being in some sense better than some of the others.)

And, of course, we do know of some ways to compare the strengths and drawbacks of at least some pairs of metaphysical theories. I'll give an example of the kind of thing I mean. I intend in this paper to present parts of a metaphysical theory (not to defend it; rather it will serve as an illustration of a theory that, as my title implies, dispenses with ontological levels). Suppose that I were to set out to compare this metaphysical theory with some theory of the gen- 
eral kind endorsed by Jonathan Schaffer in his important recent paper "On What Grounds What." I find it easy to predict the items that would figure in a debate between Schaffer and me about the relative merits of the two theories. For his part, he would say that my theory rests on an unworkable conception of metaphysics and that it contains a disguised but essential appeal to grounding. And I would give reasons in support of my conviction that his theory is vitiated by its failure to distinguish between sentences and propositions (a distinction that is pedantic in many philosophical contexts, but crucial in the context that Schaffer's subject-matter has placed him in). I would give reasons in support of my conviction that his theory - the parts of it that have any meaning at all — incorporates, explicitly or tacitly, various theses that are simply false. For example - this is one of his tacit theses - , the thesis that the existence questions that are commonly disputed in metaphysics are best understood as questions about whether certain proper and common nouns that have a firm place in our everyday or scientific or philosophical discourse — 'God', 'Sherlock Holmes', 'property', 'number', 'mereological sum' — have (whichever is appropriate) referents or non-empty extensions.

It will, of course, be controversial whether any given theory really does have any of the features that I have imagined Shaffer and me ascribing to each other's theories, but I doubt whether there are many philosophers who would deny that the following features constitute defects in such theories as may have them: resting on an unworkable conception of metaphysics; making a disguised but essential appeal to a thesis such that the inventors of the theory formulated it with the specific intention that it should not commit its adherents to that thesis; failure to observe a crucial distinction; depending essentially on vocabulary that means nothing at all; incorporating false theses. So — the Good Way tells us — to determine whether metaphysics needs ontological levels, examine proposed theories, not supposed cases: examine (on the one hand) theories that imply that there are indeed things that occupy distinct ontological levels, and (on the other) theories that imply either that the very concept of an ontological

\footnotetext{
${ }^{2}$ Included in David Chalmers, David Manley, and Ryan Wasserman (eds.) Metametaphysics: New Essays on the Foundations of Ontology (Oxford: Oxford University Press, 2009), pp. 347-383).
} 
level is in some way defective or that there is only one ontological level. Compare these theories in respect of matters like the incorporation of meaningless or false statements, having unnoticed entailments that demonstrably unfit them for the metaphysical work their authors intended them to do, and so on. (One will of course want to consider the virtues as well as the vices of the theories in question but I refrain from naming any theoretical virtues because it is hard, very hard indeed, to find plausible and non-trivial examples of theoretical virtues that can be described in the brief compass appropriate to an illustrative example.) The Good Way tells us that the only real argument for the existence of pairs of things that occupy distinct ontological levels, the only argument worth paying attention to, is this: a theory according to which there are such pairs emerges from this dialectic as clearly superior to all theories according to which there are not. And, of course, the Good Way tells us the same thing, mutatis mutandis, about arguments for the non-existence of such pairs.

You have no doubt inferred, and inferred correctly, that my advice to those who try to answer the "levels" question is to follow the Good Way. If you are comfortable with the idea of metaphysical intuitions (I'm not, not really, but you may be), my advice could be put like this: Apply your metaphysical intuitions to carefully stated and well-worked-out and very general theories, not to particular examples or individual cases. Examples can, of course, figure in the comparison of theories: one can compare the ways in which rival theories deal with particular examples. But don't first - before considering any theory - decide what to think about some range of examples, and then use the set of conclusions you have reached by considering each case individually as a fixed store of data to draw on when you are evaluating competing metaphysical theories.

My purpose in this paper is simply to give an outline of the metaphysical theory I favor — or, at any rate, of the part of this theory that is particularly relevant to the question of ontological levels: the ontology I favor. It will emerge that there is no place in this ontology for the concept of ontological levels or for the designation of certain entities as ontologically fundamental or for ontological grounding or for a special ontological status that is enjoyed by some of but not all the entities it recognizes. I do not suppose that the fact that this one ontology has no place for ontological levels is any sort of argument 
for the conclusion that metaphysics does not need ontological levels. An argument for that conclusion - the Good Way tells us - would have to consist in a comparison of all the ontologies that do not incorporate the idea of ontological levels (presumably, mine is not the only one) with the competing ontologies that do. Before any such comparative evaluation can be carried out, however, we must have the competing ontologies on the table. This paper is intended only to accomplish one part of that preliminary undertaking — to put one theory on to the table and to formulate it in a way that brings the fact that there is no place in it for the concept of an ontological level into sharp focus.

The theory that I propose to put on to the table is not the theory of material beings that I presented in the book of that name. If I were to write a systematic Summa Metaphysica in ten chapters, my theory of the metaphysics of the physical world would be presented in Chapter 9 or thereabouts. Earlier chapters, those in roughly the middle of the book, would be devoted to topics like realism versus idealism and the nature of space and time. Earlier still would be the chapters on cosmology and creation (or, more generally, on the question 'Why is there anything at all?'). The ontology that I am going to lay out in this essay would occupy the second chapter of the book. (The first chapter would contain (a) an analysis of being and existence, and (b) a development of the concept of an ontological category - a concept that I shall use without explanation in the present essay, and (c) an account of the nature of ontological disputes — disputes about, e.g., the existence of universals or temporal parts or mereological sums. The first chapter would be, in a word, an essay in what I have called "meta-ontology." And the meta-ontological position defended in that essay would be, in many respects but not all, Quine's position. In the present essay, I will presuppose a Quinean understanding of existence and being and the proper method to employ in resolving disputes about what there is.)

Although, as I say, the theory that I am going to "put on to the table" is not the metaphysic of the physical world that was set out in Material Beings, I take just a moment to insist — vehemently — that that metaphysic does not in any way involve the idea of a plurality of ontological levels. I remind you that my metaphysic of physical things does not imply that electrons inhabit a more fundamental level 
of being than that occupied by chairs. For that to be the case, there would have to be a level of being occupied by chairs, and for that to be the case, there would have to be chairs. And there are no chairs. Nor does that metaphysic imply that electrons and mice inhabit different ontological levels: electrons have no proper parts (so they say), and mice have proper parts (whatever Aristotle may have supposed), but an electron and a mouse are both equally "there," and the two phrases 'has no proper parts' and 'has proper parts' are not — at least so far as I can see - phrases that even seem to be, that so much as represent themselves as, names of ontological levels.

While we are on the topic of the physical world, I will note parenthetically that there is a clear and useful causal sense in which one physical entity can be more fundamental than another: an entity $x$ is more fundamental than an entity $y$ if $x$ can exist in a wider range of physical regimes than $y$. For example, a proton is more fundamental than a sparrow because a proton can exist in every circumstance in which a sparrow can exist and can also exist in the center of a star (an environment hostile to sparrows). A quark is by the same token more fundamental than a proton because quarks exist wherever protons exist and once existed when protons could not yet exist: in the quark-gluon soup of the Very Early Universe. It seems evident, however, this use of the word 'fundamental' is entirely unrelated to the use of the word in current metaphysics.

Let us then turn to the metaphysic, the ontology, that I am putting on the table. The first thing to say about this theory - the content of the second chapter of my imaginary Summa Metaphysica - is that it is, if I may so express myself, radically platonistic. I will try to explain what this slogan means.

According to this ontology - let us call it the Favored Ontology - - the things that there are may be exhaustively divided into two broad categories. One of them is a category that I am willing to call by any of three names: the category of universals; the category of abstract objects; the category of relations. (I so use the term 'relation' that propositions count as 0 -term relations, and qualities, properties, or attributes as 1-term or unary/monadic relations. Binary/ dyadic and ternary/triadic — and so on - relations I call "proper" relations, a class that also includes variably polyadic relations.) I do not regard these three names as equivalent in meaning. I indeed say 
that the classes "universal," "abstract object" and "relation" are identical, but when I say this I mean to be expressing a substantive metaphysical thesis. In, the sequel I will use the term "abstract object" to refer the members of this category, but the choice is more or less arbitrary and I do not mean it to imply that I regard the term 'abstract object' as a name for this category that is in any way more important or more, well, fundamental or than either 'universal' or 'relation'.

Abstract objects, I contend, exist independently of human language and human thought. For that matter, they exist independently of divine thought. Each of them in fact exists independently of $e v-$ erything - or, at any rate, of everything else, everything besides itself. Each of them is, I maintain, a necessarily existent entity: the population of abstract objects is the same in every possible world. In particular, they exist independently of the contingent things that they are potentially about, are potentially features of, and potentially relate. The proposition that George Bernard Shaw was credulous, for example, exists in all possible worlds, even though Shaw himself exists in hardly any of them. The attribute credulity likewise exists in all possible worlds, even if (as I'm inclined to suppose) credulous beings like those whose multitudinous existence is such a deplorable feature of the actual world are to be found in only a minuscule proportion of logical space.

Abstract objects are, moreover, radically anetiological. That is to say, it is not possible that they should act on other things (they lack causal powers) and it is not possible that they should be acted on by other things (they are impassible). An abstract object can, of metaphysical necessity, be neither agent nor patient. (Read that statement de dicto or de re, as you will; it's true either way.) This point applies equally to those abstract objects that are causal powers. The attribute "carries unit negative charge" (an attribute of all electrons) is a causal power, but it has no causal powers. (It's things like electrons that have causal powers - causal powers such as carrying unit negative charge.) And it is not only the case that all abstract objects are anetiological; it is also the case that only abstract objects are anetiological. Other possible names for the category "abstract object" are, therefore, 'anetiological object' and 'non-causal thing'.

Abstract objects are, finally, non-spatio-temporal. The idea of a location either in space or in time has no application to them. One 
important consequence of this thesis is that it makes no sense to say that a property is located (or wholly located) where its instances are.

The other "high" category of things, the other primary ontological category, is the category "concrete object." Like the category "abstract object," this category has more than one name, and it is a substantive metaphysical thesis that these names — which are not equivalent in meaning and none of which is more important or more fundamental than any of the others — are all names for one category. Other names for the category of concrete objects are: "substance," "impredicable," "individual thing" or "particular thing," and "agent" (or "etiological object" or "causal thing"). ("Patient" may also be a name for this category. Whether a metaphysician supposed that it was would depend on whether that metaphysician believed, with Aristotle and St Thomas, that there was one rather special substance whose nature was incompatible with patiency.)

I understand the word 'substance' in either of two senses: 'thing that cannot be predicated of things' and 'thing that exists "on its own" or "in its own right" — - that is a thing that is not a mode or mere modification of some other thing; a thing that does not "inhere in" some other thing; a thing that is not an "ontological parasite." (Obviously, Aristotelian universals, if such there be, are not substances in the second sense, but then no one would have supposed that they were, since they are not individual things. And equally obviously, individual accidents or tropes are not substances — but, again, no one would have supposed that they were. Holes and wrinkles are a more interesting case: if there are such things as holes in pieces of cheese and wrinkles in carpets, they are not substances — not even if they are space-occupying, contingently existing individual things that endure through time and have causal powers.) These are two distinct meanings that the word 'substance' might have. I contend only that the class of things that are substances in either sense is identical with the class of things that are substances in the other. (According to the Favored Ontology, there are no ontological parasites. This is presumably a necessary condition for this ontology's serving as an illustration of an ontology that has no place in it for fundamentality or ontological levels — for it seems obvious that being an ontological parasite would be sufficient for being a non-fundamental thing. I would, however, insist that a philosopher who did believe that there 
were ontological parasites should deny that they were substances.)

The category "concrete object" includes such items as shoes and ships and bits of sealing wax and cabbages and kings. (That is, it includes such things as these if there are such things - and if, as I suppose, Spinoza is wrong and these things are not mere finite modes of the one substance. Whether there are such things as shoes and ships and the rest of that lot is a question that must be referred to the final chapters of the Summa Metaphysica. At any rate, all such physical or material things as there are belong to this category. And such immaterial or non-physical or non-spatial or supernatural things as there may be belong to it as well, provided that they have causal powers: Cartesian egos, angels, Babylonian deities, God, ... . God, I will remark, must belong to this category - if he exists - simply in virtue of the fact that he has causal powers. He is a concrete thing even if, as some theists suppose, he exists necessarily, and even if, as some theists suppose, it is metaphysically impossible for anything to act on or affect him, and even if, as some theists suppose, he has no sort of location in either space or time.)

It follows from what we have said about abstract objects that they can in no possible sense of the word be constituents of concrete objects. Thus, the Favored Ontology agrees with "austere nominalism" on one important point: concrete objects have no "ontological structure." They are what Armstrong has called "blobs." The only constituents of concrete objects are their proper parts (parts in the strict and mereological sense): "smaller" concrete objects. For example, the only constituents ships have (if ships there are) are concrete things: masts and rudders and planks, perhaps, or steel plates and nails and rivets and molecules and atoms and elementary particles.

I of course recognize the fact that many metaphysicians contend that there are things of kinds that cannot, or cannot obviously, be thought of as sub-categories (or subclasses or sub-anythings) of either of the two categories I have delineated — or, for that matter, as subclasses of their union, overlapping both. We may cite:

- facts and states of affairs

- states (as in "mental state" and "physical state")

- physical quantities: masses, charges, forces,...

- immanent universals 
- $\quad$ kinds (natural or otherwise): species, genera, taxa

- tropes or individual accidents or property instances

- bare particulars or substrates

- mathematical entities: sets, numbers, vectors, functions, operators ...

- $\quad$ events (or changes) and processes

- moments and intervals of time

- $\quad$ spatial points and lines and regions

- points in and regions of space-time

- $\quad$ stuffs and quantities of stuff: water; the water in this glass

- “derivative entities" or "ontological parasites" or "modes of substance”: holes, cavities or hollows, surfaces, waves, shadows, reflections ...

- mental/perceptual/intentional entities (other than immaterial mental substances like Cartesian egos): pains, qualia, sensations, sense data, thoughts, episodes of reasoning, the witch that Hob thought had blighted his crop ...

- linguistic entities: word-tokens, sentence-types, questions, tenses, languages ...

- $\quad$ social entities: married couples, universities, football teams, political parties, religions, nations ...

The fact that it is hard — and may in some cases be impossible — to find a place for entities of these kinds in the Favored Ontology should not be taken to entail that that ontology has any implications, any implications whatever, in the matter of whether any sentences spoken in the ordinary business of life express true or false propositions. I take the ontology I propose in no way to imply that any of the following sentences cannot express truths when uttered in everyday circumstances in which their utterance would be conversationally appropriate:

There are several well-known facts that the Senator chose to overlook in her speech

For any solid object in the shape of regular cone and for any units of linear measure [yards, nanometers, light-years ...], there are real numbers $x$ and $y$ such that (a) the circumference of that object at its base is $x$ units to four significant decimal places, and its 
height is $y$ units to four significant decimal places, and (b) its volume is $x^{2} y / 37.6991$ cubic units to four significant decimal places

There are exactly as many one-centimeter holes in this board as there are one-centimeter wooden dowels in the enclosed packet

When speakers of Portuguese utter Portuguese declarative sentences in the ordinary business of life, they very often thereby say true things.

In my view a successful defense of the Favored Ontology would include ways of providing paraphrases of those natural-language sentences that both express truths and appear to involve reference to or quantification over things that are neither propositions, properties, relations, nor substances in such a way that the paraphrases (a) either express the same propositions as the originals or at least - as it were - can serve the same purposes as the originals, and (b) involve reference to and quantification only over propositions, properties, relations, and substances.

I might, for example, in attempting to provide such paraphrases say that states of affairs are just exactly propositions (the states of affairs that obtain being true propositions and the states of affairs that do not obtain being false propositions), and I might say that facts are simply states of affairs that obtain — that is, true propositions. I might first paraphrase all sentences that are couched in the standard vocabulary of applied mathematics as sentences whose only specifically mathematical vocabulary comprises the two predicates 'is a set' and 'is a member of' - and then go on to rewrite all the resulting sentences as sentences whose variables range not over sets but over properties, using the formal techniques Russell employed in his "no class" theory. I might identify kinds with their "corresponding" properties: that is, I might, e.g., identify the kind "horse" with the property equinity or horsehood. I might attempt to interpret all discourse apparently about social entities as discourse about people and various propositions they accept or have undertaken to bring about the truth of and various relations in which they stand to one another; I might, e.g, attempt to interpret discourse about religions as discourse about people and various theological propositions and various 
relations like the variably polyadic relation expressed by 'the xs are co-religionists'.

Now one might well ask, Why just those two categories? Why not none - that is, why not dispense with the concept "ontological category" altogether? Or, if you are going to make use of that concept, why not just one of those two? And why not other categories whether or not those other categories are employed in conjunction with one or both of the categories "abstract object" and "concrete object"?

My answer to the question 'Why not none?' would depend on my analysis of the concept "ontological category," and that is not a task I am prepared to undertake in within the confines of this essay.

If the question is, Why not only one of your two categories?, this question will make sense only if that "one" is the category "concrete object" - for it is obviously an absurd thesis that there are only abstract objects: if there are only abstract objects, what are we and what is "all this" (imagine that I have spoken those words aloud and have accompanied them with a gesture obviously intended to indicate "all around I see")? I am of course aware that there are ontologies according to which everything is a "property." There is Laurie Paul's ontology, for example, or James Van Cleve's "New Bundle Theory" (invented by him, but not endorsed by him). But the "properties" that are the members of the sole category endorsed by such theories cannot be what I am calling "properties" — since they, or some of them, can be present in various regions of space and since they, or some of them, can enter into causal relations (some of them are visible, for example).

Suppose the question is, Why does your ontology include abstract objects? Why not only concrete particulars? Why not only substances? Why are you not a nominalist? I have answered this question elsewhere: I should very much like to be a nominalist, but I can't see my way clear to being a nominalist. I can't see my way clear to being a nominalist because I don't like contradicting myself, and I find that I can't get along in the world without saying things that imply the existence of abstract objects - or at least they seem to me to have that implication, and I can find no very convincing reason to suppose that that seeming is mere seeming. But this confessional statement raises large questions that I cannot address here. 
Why, then, do I not employ other categories? Why does my ontology not include states of affairs - states of affairs that are not propositions but are rather the truth-makers for propositions? Why does it not include states - mental states and physical states, conceived as things that have causal powers? Why, for God's sake, does it not include events? And so on and so on.

To this series of questions there is a long answer and a short answer. To present the long answer I should have to write a book or at any rate a monograph. I choose to present only the short answer. It can, I hope, be given in the form of an example — followed by an attempt to generalize the moral of that example. The example is this: I will try to explain why my ontology does not include events.

Let us consider one of those pokers that were apparently an invariable adjunct to life in the rooms of Trinity College a century ago. The poker is cold; it is placed in the fire and becomes hot. That is to say, a certain substance, the poker, acquires a certain property, the property "being hot." Why not say that the poker's acquisition of the property "being hot" entails the existence of a third item (an item identical with neither the poker nor the property "being hot"), an item denoted by the very words I have used: 'the poker's acquisition of the property "being hot"? And, of course, if the description 'the poker's acquisition of the property "being hot"' denotes something, what it denotes is a certain event, a certain change in the way things are.

I have imagined that I have been asked the question, "Why not say that there are events?" But the ghost of Occam is whispering another question in my ear: Why say that there are events? Why multiply entities beyond necessity? Now you may want to tell me that to affirm the existence of events is not to "postulate" them - any more than to affirm the existence of Scotsmen or camels or historians of medieval philosophy is to postulate something. We already believe in the existence of events, you may want to tell me: earthquakes and lovers' trysts and traffic accidents are items in everyone's ontology. And if we do allow the term 'postulate' (I imagine your continuing), in postulating the existence of events, we're hardly postulating beyond necessity: we can't say what we need to say without referring to and quantifying over events.

These questions are not easily answered in a brief compass. I will attempt to answer only the second, and I cannot devote to it the 
space that it deserves. I say that to affirm the existence of events, whether you call it postulating or not, is to affirm the existence of items one doesn't need to affirm, since it is possible to paraphrase all sentences that involve reference to and quantification over events as sentences that involve only reference to and quantification over substances and properties. (And, I contend, these paraphrases will be workable substitutes — but for length and complexity — for their originals, whether those originals figured in scientific explanations, in philosophical arguments, or in the conduct of the ordinary business of life.) I cannot defend this thesis here: my purpose in stating it is only to point out that it is the thesis I am putting forward when I say that it is not necessary to affirm the existence of events.

You may reply that the argument is insufficient. After all, in that wonderful ironic fragment called "Ontological Misogyny," Alonzo Church showed how to paraphrase away all reference to and quantification over women. And yet women exist: they inhabit the realm of being in serene indifference to Church's splendid logical tour de force. ${ }^{3}$ And, for all logic can tell us, it may well be that there are events despite the fact (if fact it is) that it is possible to eliminate quantification over events from our discourse. What logic can tell us is the following: If Olivia the ontologist — whose taste for desert landscapes has led her to embrace the proposition that she inhabits an event-free world — has a way of paraphrasing those of the sentences she wishes to utter that apparently imply the existence of events (Olivia, of course, holds that this appearance is mere appearance) in such a way that the sentences her method yields do not even apparently imply the existence of events, then she is in a position to say practically useful everyday things like 'The commission's report contains a detailed description of the sequence of events that led up to the release of radioactive material into the atmosphere' and to say theoretically useful metaphysical things like 'There are no events' and, nevertheless, to avoid (perhaps) contradiction, and (certainly) the appearance of contradiction.

3 “Ontological Misogyny" (also known as “The Ontological Status of Women and Abstract Entities") is available at several places on line. Two of them are http://www.jfsowa.com/ontology/church.htm and http://cs.nyu.edu/pipermail/fom/2005-September/009079.html. 
I can, moreover, cite a more important motivation than a mere love of ontological parsimony for refusing to affirm the existence of events. It is this. It is not at all clear to me that it is possible to assign a complete and consistent set of properties to objects of that alleged kind. I take it to be obvious, a mere matter of logic, that everything has, for any property, either that property or its complement. In other words, any meaningful question about either objects of a certain kind or about any given object of that kind must have an answer. And it seems to me that if there are events, there are many clearly meaningful questions that can be asked about them (general questions, questions about the category "event" and questions about the supposed referents of certain singular descriptions that purport to denote events) that have no answers. It may be that a theory of events would answer certain of these questions. For example: Can an event recur?, or What is the relation between, e.g., the object called "the poker's becoming hot at noon" and the poker? (The poker must in some sense be a "constituent" of the poker's becoming hot at noon — but what, precisely, is this "constituency"?) I am less sanguine about the possibility of answering questions like those posed in the following example.

Consider a certain gradual acquisition of the property "being hot" by the poker in McTaggart's study, an event that occurred in the morning of on March 11th, 1905; to be more precise, it started at 9:03 a.m. and went on till 9:09 a.m. Here're some questions about that event. Could it have happened earlier or later? - and, if so, how much earlier or how much later? Could it have happened over a longer or shorter period of time? And here're some more questions about it. The poker, on that occasion, reached a maximum temperature of $487^{\circ} \mathrm{C}$; would it still have occurred if the poker had reached a significantly higher temperature, or if it had reached only a significantly lower one? Only certain parts of the poker reached $487^{\circ} \mathrm{C}$; suppose it was other parts of the poker that had reached that temperature. Would it nevertheless have occurred?

I cannot show that there could not be a marvelous theory of events that implied that all these questions had answers, but I would ask why one should bother to try to find or construct such a theory, however 
marvelous, if apparent reference to and apparent quantification over events can be eliminated from our discourse. Why should we metaphysicians invest the precious and severely limited time that is given to us for serious metaphysical thinking in an attempt to find answers to intransigent questions if we can make the questions go away?

I think it is important to note that an appeal to ontological levels or grounding or ontologically fundamentality does nothing to enable us to resolve these questions (to answer them or to deal with them in any other way - for example, to dismiss them as meaningless or somehow illegitimate). Suppose we assume that certain entities substances and properties, it may be, but pick any entities you like are ontologically fundamental and that events, although there indeed are events, are not among these ontologically fundamental entities. That is to say, assume, that events are ontologically grounded in the fundamental entities, that their existence and their properties and the relations they stand in to one another and to the fundamental entities are all somehow "automatically generated" by the existence of and the properties of and the relations that hold among the fundamental entities. Still, events exist. They're really there. Apparent reference to and quantification over them is not mere appearance. They do not, as it were, disappear when the sentences that apparently imply their existence are subjected to careful logical or ontological analysis. And that means, as I have said, that each of them has, for every property, either that property or its complement. And that implies that all the questions I have asked must have answers. This is the moral of my example, the moral I promised to generalize.

And the generalization is obvious: it is a defect in a metaphysical theory if it affirms the existence of things that raise questions that have no answers. And it is a prima facie defect in a metaphysical theory if it affirms the existence of things that raise questions such that those who espouse the theory are at a loss to provide answers to them. And that is why I have chosen substances and relations as the only entities whose existence my theory affirms. I do not mean to imply that I can solve all the problems that these entities raise — or all the questions that must by answered by the metaphysician who affirms the existence of substances and relations and nothing else. ${ }^{4}$

\footnotetext{
${ }^{4}$ There are three problems in this area that I know of no fully satisfactory
} 
I can say only that:

(a) I don't think that substances and relations can be dispensed with; I don't see how to "paraphrase away" the apparent reference to and quantification over substances and relations that is a pervasive feature of our everyday and philosophical and scientific discourse. I think, therefore, that such problems as are raised by substances and relations are unavoidable.

(b) I do think that all the other entities of the sorts whose existence might be affirmed by a metaphysician writing, in my trope, Chapter 2 of a Summa Metaphysica (i) raise intransigent questions comparable with those I raised in my brief discussion of events, and (ii) can be dispensed with. If I do not in every case know how to do this (see $n$. 3), I am willing to include in my "research program" the search for techniques of paraphrase that will enable us to dispense with the entities whose "dispensability" is still problematical. I regard the problem of finding suitable techniques of paraphrase as tractable.

(c) There is no place for the concept of entities that occupy different ontological levels in a metaphysical theory that affirms the existence of only of substances and abstract objects (understood in the "radically platonistic" sense endorsed by the Favored Ontology). And, therefore, there is no place in such a metaphysical theory for the concept of entities that are ontologically grounded in other entities or the concept of entities that are ontological fundamental. Substances are not grounded in abstract objects, and abstract objects are not

solution to.(i) It looks for all the world as if (given that there are properties at all - given that there are unary or monadic relations) when one says — and, surely, this is true? - "The property 'wisdom' is not one of its own properties," one is ascribing the property expressed by the open sentence ' $x$ is not one of the properties of x' to wisdom. But, as Russell has taught us, if there is such a property it has itself if and only if it does not have itself. (ii) I do not know how to find logically satisfactory systematic names for certain relations - such as asymmetrical binary relations. (For a discussion of this problem, see my essay, "Names for Relations," Philosophical Perspectives, Vol. 20: Metaphysics (2006) pp. 453-477.) (iii) I am not sure how to represent quantification over places and times within the confines of the Favored Ontology. 
grounded in substances. Nor are some substances grounded in other substances or some abstract objects grounded in other abstract objects - not, at any rate, in any sense of "grounded in" that at all resembles the sense in which, e.g., the set that contains Socrates and nothing else - a standard example of an entity that is said to be grounded in an entity of another sort - , is said to by those who use this example to be grounded in Socrates. Substances and abstract objects, moreover, do not occupy different ontological levels. They belong to radically different ontological categories, yes, but there is nothing that could be meant by saying that one of these categories was more fundamental than the other. Nor do any two substances occupy different ontological levels ${ }^{5}$. Nor, finally, do any two abstract objects occupy different ontological levels.

Anyone who accepts the theory I have outlined (the Favored Ontology) has thereby "dispensed with ontological levels." As I have said, this fact by no means constitutes an argument for the conclusion that metaphysicians should reject the concept of objects that occupy distinct ontological levels. An argument for that conclusion could (as I have said) emerge only in the course of a systematic and comprehensive comparison of, on the one hand, the defects and merits of the metaphysical theories that, like the Favored Ontology, do not incorporate the idea "ontological level," and, on the other, the defects and merits of the metaphysical theories that do incorporate this idea.

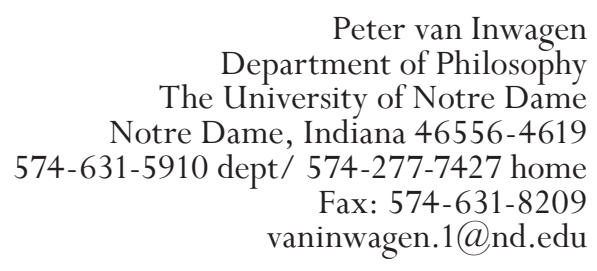

\footnotetext{
${ }^{5}$ In my view, this statement is fully consistent with classical theism. There is certainly a sense in which God and creatures occupy different ontological levels, but it is not - it in no way resembles — the sense in which "singleton Socrates" and Socrates (supposedly) occupy different ontological levels.
} 


\section{References}

Schaffer, Jonathan. 2009. On What Grounds What. In Metametaphysics: New Essays on the Foundations of Ontology. Edited by David Chalmers, David Manley and Ryan Wasserman. Oxford: Oxford University Press.

Church, Alonzo. 1958. Ontological Misogyny. (Also known as "The Ontological Status of Women and Abstract Entities".) Available online at http:// www.jfsowa.com/ontology/church.htm and http://cs.nyu.edu/pipermail/ fom/2005-September/009079.html.

Inwagen, Peter van. 2006. Names for Relations. In Philosophical Perspectives, Vol. 20: Metaphysics. Wiley-Blackwell. 